\title{
Alvarado Score, Ultrasound, and CRP: How to Combine Them for the Most Accurate Acute Appendicitis Diagnosis
}

\author{
Sonay Aydin, ${ }^{1,}$ Erdem Fatihoglu ${ }^{1}$ Hayri Ramadan, ${ }^{2}$ Bilge S. Akhan, ${ }^{1}$ and Enver N Koseoglu ${ }^{1}$ \\ ${ }^{1}$ Department of Radiology, Ankara Training and Research Hospital, Ankara, Turkey \\ ${ }^{2}$ Department of Emergency Medicine, Ankara Training and Research Hospital, Ankara, Turkey \\ "Corresponding author: Sonay Aydin, Department of Radiology, Ankara Training and Research Hospital, 06340, Cebeci, Ankara, Turkey. Tel: +90-5066259155, Fax: \\ +90-3124179410, E-mail: sonaydin89@hotmail.com
}

Received 2016 April 03; Revised 2016 October 08; Accepted 2016 December 02.

\begin{abstract}
Background: The aim of the current study was to investigate whether the usage of three diagnostic methods of acute appendicitis which are Alvarado score, C- reactive protein (CRP) levels and ultrasound (US) in combination improves diagnostic accuracy significantly.

Patients and Methods: Data were analyzed in 254 patients with suspected appendicitis who had a sonographic examination and a CRP value. The patients were classified into four groups according to both Alvarado score and US findings. US results, Alvarado score, and CRP levels were compared.

Results: The most specific test among three diagnostic methods was sonography. Combination of an Alvarado score higher or equal to 5, a high CRP level $(\geq 0.8)$ and a sonographic examination as appendicitis with visualization of an inflamed or perforated appendix was more specific than US alone. An Alvarado score higher or equal to $5(86.2 \%)$ was found to be the most sensitive criteria. Conclusions: Using Alvarado score, US and CRP levels in combination provides us to confirm or rule out acute appendicitis safely.
\end{abstract}

Keywords: Alvarado Score, Appendicitis, CRP, Ultrasound

\section{Background}

Acute appendicitis is the most common cause of surgical acute abdomen with an estimated lifetime prevalence of $7 \%$ (1). Although acute appendicitis has a high prevalence, its diagnosis still remains challenging. The clinical presentation is generally atypical and symptoms often overlap with other conditions. The main decision for a patient with suspected acute appendicitis is whether to operate him or not. The expected goal is prompt treatment of all cases without unnecessary surgical interventions and diagnostic tests. There are various methods to diagnose acute appendicitis, Alvarado scoring system, radiological methods including ultrasound (US), computerized tomography (CT), and magnetic resonance imaging (MRI), laboratory tests including $C$ reactive protein (CRP) and white blood cell count (WBC).

CT has high sensitivity (98.5\%) and specificity (98\%) in the diagnosis of acute appendicitis; however, ionizing radiation limits its use. US with a sensitivity of $83.7 \%$ and a specificity of $95.9 \%$, when compared to CT, has advantages like lack of ionizing radiation, no contrast material use, and short acquisition time (2).

Alvarado scoring system includes clinical signs and symptoms and a differential leukocyte count (Table 1). Historically, Alvarado score is more specific than being sensi- tive, with a high positive predictive value (PPV) $(2,3)$. However, in literature there are prospective studies to suggest that Alvarado score alone is inadequate as a diagnostic test. The sensitivity and specificity largely vary between studies $(2,4)$.

\begin{tabular}{|c|c|}
\hline & Score \\
\hline \multicolumn{2}{|l|}{ Symptoms } \\
\hline Migratory right iliac fossa pain & 1 \\
\hline Nausea/Vomiting & 1 \\
\hline Anorexia & 1 \\
\hline \multicolumn{2}{|l|}{ Signs } \\
\hline Tenderness in the right iliac fossa & 2 \\
\hline Rebound tenderness in the right iliac fossa & 1 \\
\hline Elevated temperature & 1 \\
\hline \multicolumn{2}{|l|}{ Laboratory Findings } \\
\hline Leukocytosis & 2 \\
\hline Shift to the left of neutrophils & 1 \\
\hline Total & 10 \\
\hline
\end{tabular}


CRP is an acute phase reactant, which increases between 8 - 12 hours after the onset of an inflammatory process with a peak between 24 and 48 hours. It may serve as a useful predictor for appendiceal perforation, but its diagnostic utility in early simple acute appendicitis is limited $(2,5)$.

\section{Objectives}

In the current study, our purpose was to evaluate whether combination of the three methods, Alvarado score, CRP levels and US, improves diagnostic accuracy significantly.

\section{Patients and Methods}

\subsection{Patients}

Between August 2014 and January 2015, patients who were clinically suspected of acute appendicitis, and referred by the physician to the department of radiology for US examination were retrospectively included in the present study. The patients whose physical examination notes are not sufficient for Alvarado scoring and the ones who did not have a CRP level on the same day they were medically examined were excluded from the study (28 patients were excluded according to this criteria). Patient distribution is demonstrated in Figure 1. The rate of negative appendectomy varies between $15 \%$ and $30 \%$ in the literature. In 95\% confidence interval of sample size, and accepting the negative appendectomy ratio as $30 \%$, it was calculated that the study population should consist of at least 174 patients. 254 patients were included in the study ( $\mathrm{n}=$ 254 ); 148 men, 106 women with a median age of 26 ( $\min 4$, $\max 85)$.

\subsection{Alvarado Scoring}

The medical examination charts were used to calculate each patient's Alvarado score and the probability for acute appendicitis. After calculation, patients were categorized into four groups according to Alvarado score:

(i) Not possible (Alvarado score $\leq 4$ );

(ii) Possible (Alvarado score 5, 6);

(iii) Probable (Alvarado score 7, 8);

(iV) Very probable (Alvarado score $\geq 9$ ).

\subsection{CRP Levels}

Laboratory reports belonging to the same day that medical examination was performed were reviewed to acquire CRP levels.

\subsection{Sonographic Examination}

Sonographic criteria for the inflamed appendix was identification of the appendix as a fluid-filled, noncompressible, blind-ended tubular structure with a diameter greater or equal to $6 \mathrm{~mm}$. Secondary signs of appendicitis were increased echogenicity of the surrounding pericaecal fat, local fluid collection, or local dilatation of the bowel without peristalsis, indicating focal peritonitis (6).

Ultrasound scans were performed by radiologists who had no information about the patients' Alvarado scores at the time of sonographic examination. Sonographic results were classified into four groups:

(1) Normal appendix (diameter $<6 \mathrm{~mm}$ ) visualized (Figure $2 \mathrm{~A}$ and $\mathrm{B}$ )

(2) Appendix not visualized and no secondary signs of appendicitis

(3) Appendix not visualized, but one or more of the secondary signs were established

(4) Appendicitis with visualization of an inflamed or perforated appendix (Figure $3 \mathrm{~A}$ and $\mathrm{B}$ ).

\subsection{Diagnosis}

Diagnosis of acute appendicitis was based on pathological results. Acute appendicitis was excluded by negative pathological results, presence of any other final diagnosis, resolved symptoms during observation, lack of appendectomy, or having a negative abdominal computed tomography result.

The Alvarado score, CRP level, and sonographic result of the same patient were recorded by different researchers. For instance, a researcher who knew the patient's Alvarado score was not aware of the other findings.

\subsection{Statistical Analysis}

All study information was recorded on patient data sheets, then entered into an Excel (2007, Microsoft Corp., Redmond, WA) spreadsheet for analysis. All data entries were double-checked by one of the investigators. Data were analyzed using Statistical Package for the Social Sciences (SPSS) for Windows 20 (IBM SPSS Inc., Chicago, IL). Normal distribution of the data was evaluated with the Kolmogorov-Smirnov test. Numeric variables that had a normal distribution were showed as mean \pm standard deviation. The variables that did not have a normal distribution were shown as median (interquartile range). For comparison of the numeric variables between the two groups student's $\mathrm{T}$ test and Mann-Whitney $\mathrm{U}$ test were used. ANOVA and Kruskall Wallis $\mathrm{H}$ test was utilized for comparison between three or more groups. To evaluate 


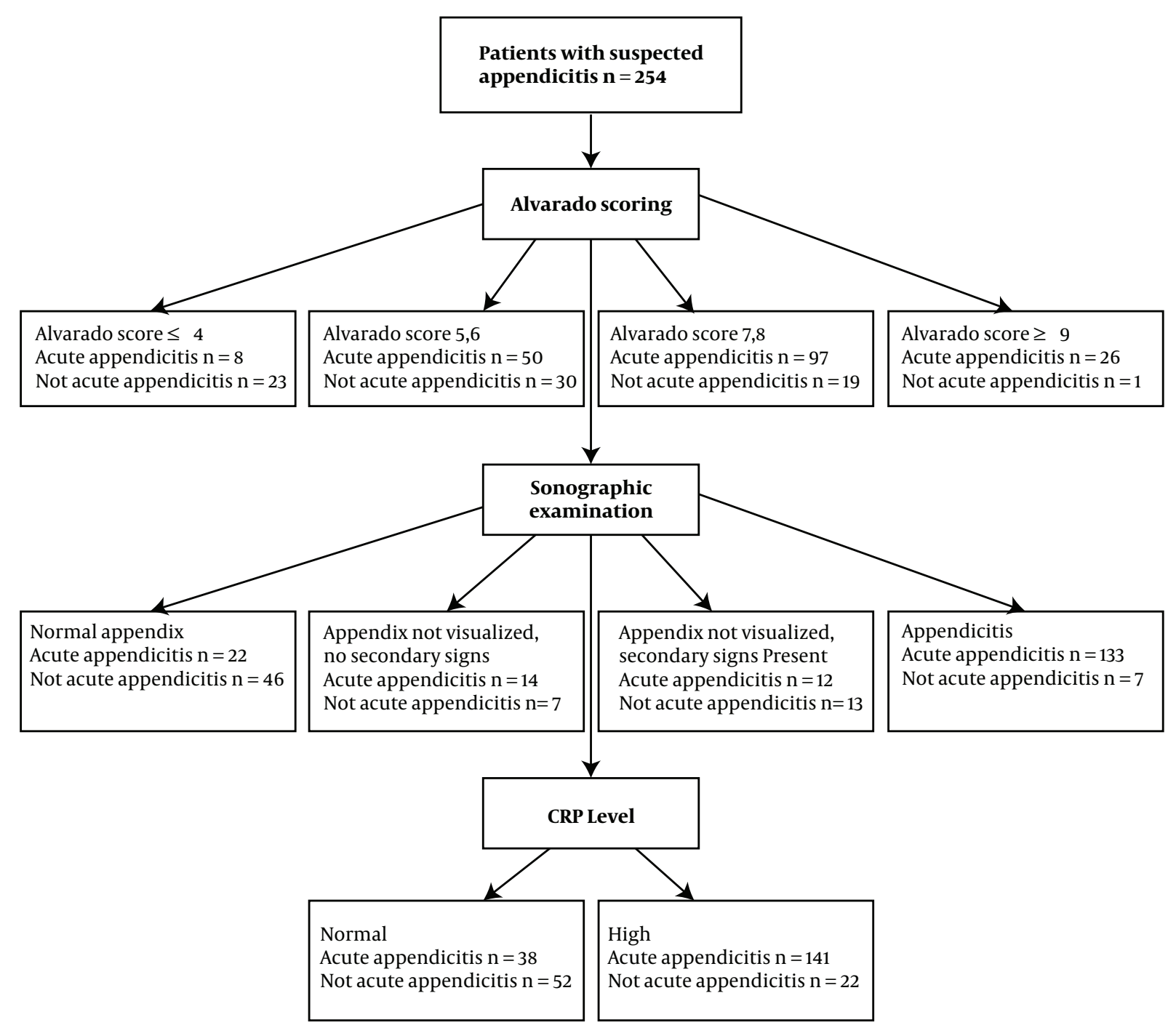

Figure 1. Flow diagram explaining patients' distribution and evaluation process

the categorical variables, Chi-Square and Fisher's Exact ChiSquare tests were used. Pearson and Spearman correlation analysis was utilized to evaluate the relationship between numeric variables.

Sensitivity, specificity, positive predictive value (PPV), negative predictive value (NPV), and receiver operating characteristic (ROC) analysis were used to assess the performance of three diagnostic parameters (Alvarado score, US, and CRP). P value of less than 0.05 was considered statistically significant.

The study was approved by the institutional review board of our hospital, with waiver of written informed consent.

\section{Results}

\subsection{Patients' Diagnosis}

The prevalence of appendicitis, confirmed via pathological results was 71.3\% (181/254) in the present study. $7.9 \%$ (20/254) of the patients were operated, but their pathological results were not acute appendicitis. Among this group, 12 patients were reported as lymphoid hyperplasia (five patients in US group 4, seven patients in US group 3). One patient was reported as parasitic infestation (US group 4). Seven patients were reported as normal appendix (one patient in US groups 1, 3 and 4; four patients in US group 2) by pathology. 

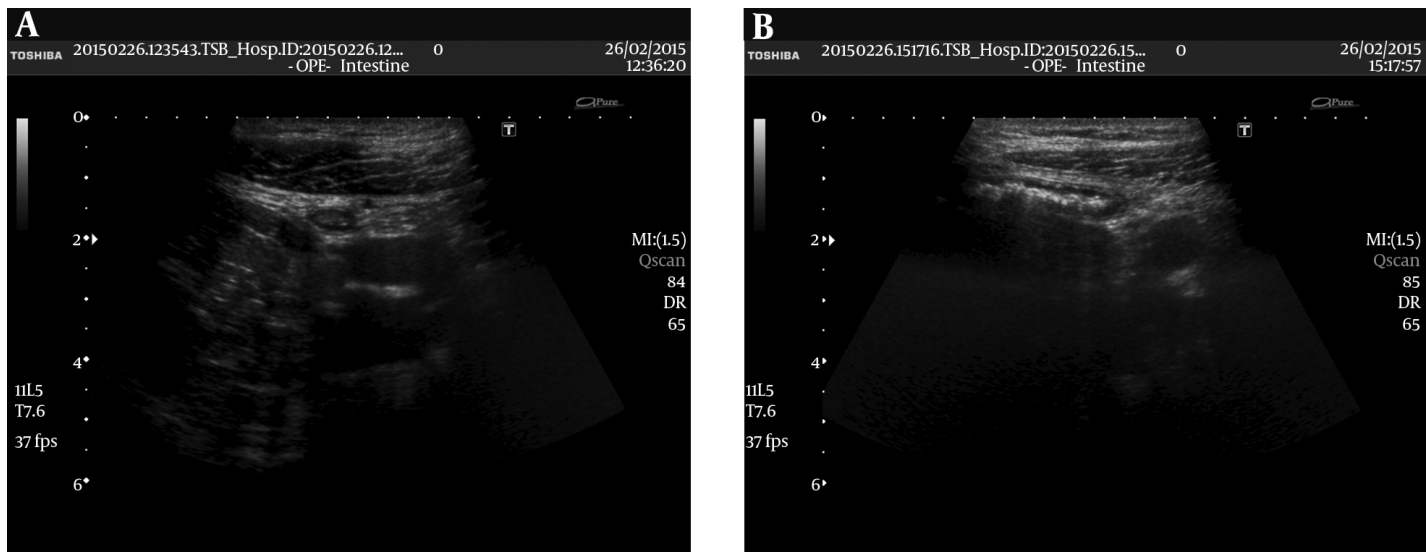

Figure 2. Normal appendix (A) transverse and (B) longitudinal views obtained with a 7 MHZ linear probe. There is no sign of inflammation/increased echogenity, lymph nodes or free fluid in surrounding tissue. The patient was included in US group 1 . Appendix vermiformis is pathologically confirmed to be normal.
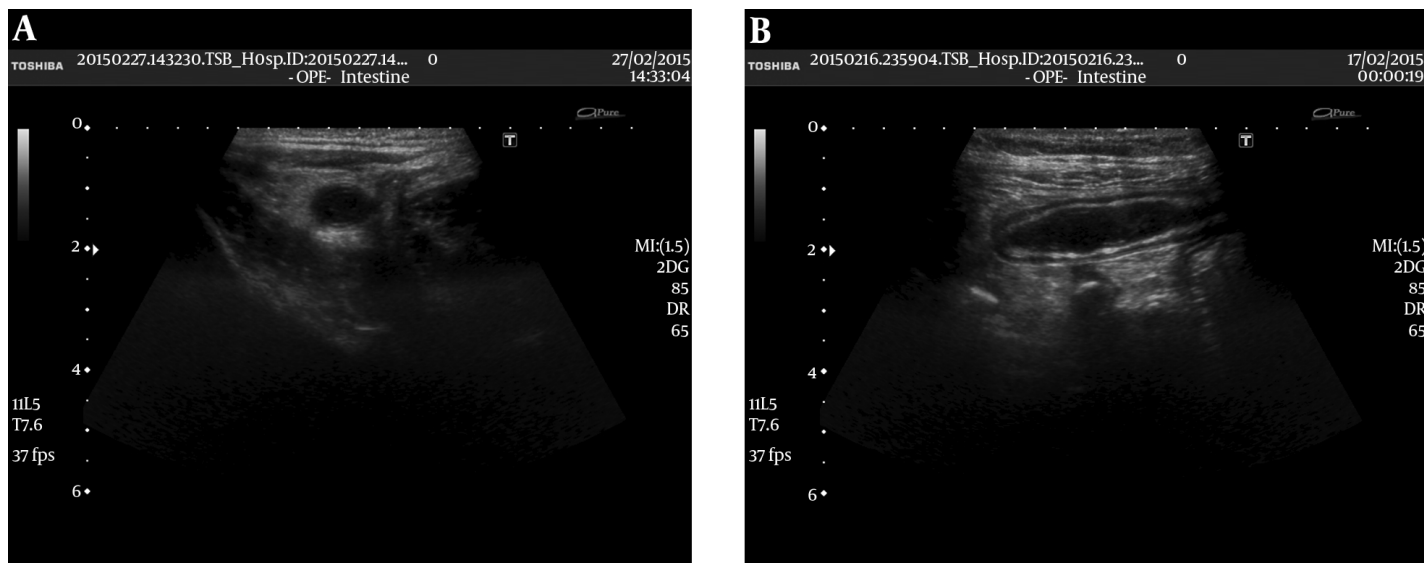

Figure 3. Inflamed appendix (A) transverse and (B) longitudinal views obtained with a $7 \mathrm{MHZ}$ linear probe. Appendix vermiformis is enlarged and hypoechoic. Wall of the appendix is also enlarged. Periappendiceal fat is hyperechoic secondary to inflammation. The patient was included in US group 4. Appendix vermiformis is pathologically confirmed to be inflamed.

20.9\% (53/254) of the patients had a clinical diagnosis other than acute appendicitis.

\subsection{Results of US Subgroups}

Patients' distribution according to US findings is shown in Table 2. Among US group 1, none of those with normal CRP values and normal Alvarado scores $(16.1 \%$; 11/68), were diagnosed as acute appendicitis by pathology. Among US group 4, all of the cases with an Alvarado score more than 6 and a CRP value higher than $4 \mathrm{mg} / \mathrm{L}$ (31.4\%; 44/140) were diagnosed as acute appendicitis by pathology.

\subsection{Alvarado Scores}

Minimal Alvarado score is 2, maximal is 10 and mean Alvarado score of the population is calculated as $6.6 \pm 1.6$. Pa-
Table 2. Distribution of Patients into Ultrasound Groups

\begin{tabular}{lc}
\hline Ultrasound Group & Percentages (Numbers) \\
\hline $\mathbf{1}$ & $26.8 \%(68 / 254)$ \\
$\mathbf{2}$ & $8.3 \%(21 / 254)$ \\
$\mathbf{3}$ & $9.8 \%(25 / 254)$ \\
$\mathbf{4}$ & $55.1 \%(140 / 254)$ \\
\hline
\end{tabular}

tients' distribution according to Alvarado score is shown in Table 3. 
Table 3. Distribution of Patients into Alvarado Score Groups

\begin{tabular}{lc}
\hline Alvarado Score Group & Percentages (Numbers) \\
\hline i & $12.2 \%(31 / 254)$ \\
ii & $31.5 \%(80 / 254)$ \\
iii & $45.7 \%(116 / 254)$ \\
iv & $10.6 \%(27 / 254)$ \\
\hline
\end{tabular}

\subsection{CRP Levels}

CRP levels in our study population changed between minimum 0, $1 \mathrm{mg} / \mathrm{L}$ and maximum $43 \mathrm{mg} / \mathrm{L}$, and the median CRP level was $2.5 \mathrm{mg} / \mathrm{L}$ (normal range of CRP in our hospital's laboratory was less than $0.8 \mathrm{mg} / \mathrm{L}$ ). Median CRP levels of each patient group are demonstrated in Table 4.

Table 5 compares sonographic results, Alvarado score components and median Alvarado scores, median CRP levels according to final diagnosis (acute appendicitis, not acute appendicitis, and any other clinical diagnosis). In acute appendicitis group, there was a significantly higher occurrence of migratory right iliac fossa pain, rebound tenderness in the right iliac fossa, leukocytosis, and shift to left of neutrophils $(\mathrm{P}=0.001)$. The sonographic result of these cases was also significantly more likely to be in group $4(\mathrm{P}<0.05)$. On the contrary, elevated temperature had a significantly higher occurrence in any other clinical diagnosis group $(\mathrm{P}<0.05)$. A higher mean Alvarado score also had a significantly higher occurrence in pathologically confirmed acute appendicitis group $(\mathrm{P}=0.001)$. Median CRP levels were higher in acute appendicitis group (acute appendicitis $3.8 \mathrm{mg} / \mathrm{L}$; not acute appendicitis 0.7 $\mathrm{mg} / \mathrm{L}$; not operated/any other clinical diagnosis $0.4 \mathrm{mg} / \mathrm{L} \mathrm{P}$ $<0,001)$.

Statistical significance of mean Alvarado scores and median CRP levels were also evaluated according to sonographic results. Mean Alvarado score was significantly higher in US group 4. (Group 1 = 5.9 \pm 1.7 ; group $2=6.7 \pm 1.8$; group $3=6.0 \pm 1.8$; group $4=7.0 \pm 1.4)(\mathrm{P}<0.001)$. Median CRP levels also had a significantly higher value in US group 4 (Group 1=0.5 mg/L; group 2 =3.3 mg/L; group 3=2.0 mg/L; group $4=3.5 \mathrm{mg} / \mathrm{L})(\mathrm{P}=0.001)$. When sonographic groups and final diagnosis were compared, it was seen that in US group 4, 95\% (133/140) of the patients had the diagnosis of acute appendicitis while in US group 1, this rate was 32.4\% (22/68).

A high CRP level $(\geq 0.8)$ with a sensitivity of $78.5 \%$ and a specificity of $69.9 \%$ was detected to be a probable predictive value for acute appendicitis (AUC $\pm \mathrm{SE}=0.737 \pm 0.040$ ) $(\mathrm{P}<0.001)$. An Alvarado score of $\geq 5$ with a sensitivity of $86.2 \%$ and a specificity of $59 \%$ was detected as a probable predictive value for acute appendicitis $(\mathrm{AUC} \pm \mathrm{SE}=0.776 \pm$ 0.033) $(\mathrm{P}<0.001)$.

Table 6 demonstrates diagnostic performances of each Alvarado score component. The most specific component was migratory right iliac fossa pain (90.4\%), and the most sensitive component was rebound tenderness in the right iliac fossa (98.9\%). The highest NPV belonged to two components, shift to the left of neutrophils (57. 6\%) and leukocytosis (56.5\%). The component to have the highest PPV was migratory pain in right iliac fossa (92.5\%). The area under the curve (AUC) values of migratory right iliac fossa pain, leukocytosis, shift to the left of neutrophils and rebound tenderness in the right iliac fossa components are closer to each other and higher than the other components. Between these components, leukocytosis and shift to the left of neutrophils had the highest diagnostic accuracy.

The diagnostic value of each method (US, Alvarado score, and CRP) and combinations of these methods (Combination 1: Alvarado score of $\geq 5$ and a high CRP level ( $\geq$ 0,8 ); Combination 2: Alvarado score of $\geq 5$, a high CRP level $(\geq 0,8)$ and a sonographic examination as appendicitis with visualization of an inflamed or perforated appendix) are also evaluated (Table 7).

AUC, specificity and PPV values are evaluated for US, CRP, and Alvarado score, the highest values are obtained for US. However, diagnostic accuracies of all three methods are closer to each other. PPVs for Combination 1 and 2 are closer to US, but AUC value of US is higher. According to these findings, when specificity, PPD, diagnostic accuracy, and AUC values are taken into consideration, US is more diagnostic compared to the other methods $(\mathrm{P}<0.042)$. The diagnostic performances of the methods are shown in Figure 4.

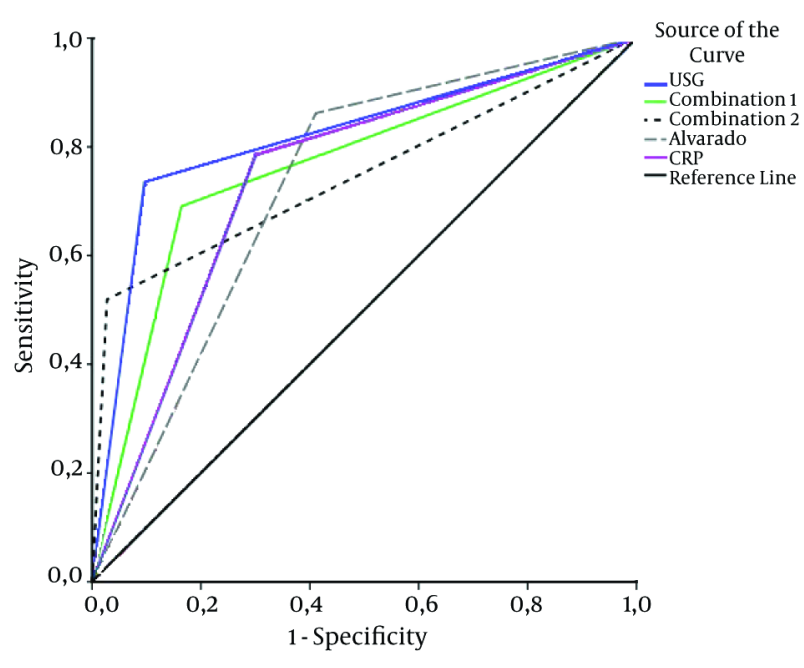

Figure 4. The curve showing diagnostic performances of the methods 
Table 4. Middle CRP Levels of Patient Groups

\begin{tabular}{|c|c|c|c|c|c|c|c|c|c|c|c|}
\hline & \multicolumn{4}{|c|}{ Ultrasound Groups } & \multicolumn{4}{|c|}{ Alvarado Score Groups } & \multicolumn{3}{|c|}{ Diagnosis } \\
\hline & 1 & 2 & 3 & 4 & $\mathbf{i}$ & ii & iii & iv & $\begin{array}{c}\text { Acute } \\
\text { Appendicitis }\end{array}$ & $\begin{array}{c}\text { Not Acute } \\
\text { Appendicitis }\end{array}$ & $\begin{array}{c}\text { Any Other } \\
\text { Clinical } \\
\text { Diagnosis }\end{array}$ \\
\hline $\begin{array}{l}\text { Middle CRP } \\
\text { Levels (mg/L) }\end{array}$ & 0.5 & 3.3 & 2.0 & 3.5 & 0.7 & 1.9 & 3.5 & 5.3 & 3.8 & 0.7 & 0.4 \\
\hline
\end{tabular}

Abbreviation: CRP, C - Reactive Protein.

Table 5. Sonographic Results, Alvarado Score Components and Middle Alvarado Scores, Mean CRP Levels Compared with Final Diagnosis ${ }^{\mathrm{a}}$

\begin{tabular}{|c|c|c|c|c|}
\hline & $\begin{array}{l}\text { Pathologically Confirmed } \\
\text { Acute Appendicitis }(n=181)\end{array}$ & $\begin{array}{l}\text { Pathologically Confirmed } \\
\text { non Acute Appendicitis }(\mathbf{n}= \\
\mathbf{2 0})\end{array}$ & $\begin{array}{l}\text { Any Other Clinical } \\
\text { Diagnosis }(n=53)\end{array}$ & P Value \\
\hline Migratory right iliac fossa pain & $86(47.5)$ & $3(15)$ & $4(7.5)$ & $<0.001^{\mathrm{b}}$ \\
\hline Nausea/vomiting & $113(62.4)$ & $8(40)$ & $44(83)$ & $0.001^{\mathrm{b}}$ \\
\hline Anorexia & $143(79)$ & $14(70)$ & $43(81.1)$ & 0.584 \\
\hline Tenderness in right iliac fossa & $179(98.9)$ & $20(100)$ & $51(96.2)$ & 0.348 \\
\hline Rebound tenderness in right iliac fossa & $95(52.5)$ & $9(45)$ & $10(18.9)$ & $<0.001^{\mathrm{b}}$ \\
\hline Elevated temperature & $24(13.3)$ & $2(10)$ & $17(32.1)$ & $0.008^{b}$ \\
\hline Leukocytosis & $151(83.4)$ & $12(60)$ & $22(41.5)$ & $0.001^{\mathrm{b}}$ \\
\hline Shift to the left of neutrophils & $156(86.2)$ & $14(70)$ & $25(47.2)$ & $0.001^{\mathrm{b}}$ \\
\hline Mean alvarado score (mean \pm SD) & $7.1 \pm 1.4$ & $5.7 \pm 1.5$ & $5.3 \pm 1.6$ & $0.001^{\mathrm{b}}$ \\
\hline Middle CRP levels & $3,8(5.0)$ & $0.7(1.8)$ & $0.4(2,5)$ & $<0.001^{b}$ \\
\hline$U S^{\mathrm{c}}$ group 1 & $22(12.2)$ & $1(5.0)$ & $45(84.9)$ & \multirow{4}{*}{$<0.001^{\mathrm{b}}$} \\
\hline US group 2 & $14(7.7)$ & $4(20.0)$ & $3(5.7)$ & \\
\hline US group 3 & $12(6.6)$ & $8(40.0)$ & $5(9.4)$ & \\
\hline US group 4 & $133(73.5)$ & $7(35.0)$ & $0(0.0)$ & \\
\hline
\end{tabular}

${ }^{\mathrm{a}}$ Categorical variables are shown as number $(\%)$

${ }^{\mathrm{b}} \mathrm{P}<0.05$ statistical significance.

${ }^{\mathrm{c}}$ Ultrasound: US.

\section{Discussion}

Although diagnostic imaging of the appendix has improved over the past decade, diagnosing acute appendicitis could still be difficult. A delay in the diagnosis and management might result in appendix rupture and subsequent peritonitis $(4,7)$.

A systematic review published in 2007 (25 studies and 9,121 patients) about diagnosing equivocal acute appendicitis using US yielded a sensitivity of $83.7 \%$ and a specificity of 95.9\% (8). Another 2006 meta-analysis found similar results in both children and adults (9). A widely known criticism about utilizing US in the diagnosis of appendicitis is that it is less accurate than CT and user-dependent. On the other hand it does not contain ionizing radiation, it is quick to perform, and well-tolerated especially in the pedi- atric population $(4,10)$.

Results of our study about sensitivity and specificity of US in acute appendicitis diagnosis are slightly lower in comparison with the literature (specificity of $90.4 \%$, and sensitivity of $73.5 \%$ ). We interpret that the large patient number and that most of these patients had body mass index (BMIs) higher than 26 might be the cause of our sensitivity and specificity rates.

In the present study, US was found to have the highest diagnostic performance (AUC 0,819). Even if the overall accuracy of sonography in the diagnosis of acute appendicitis is high, some problems and limitations of US that can cause false-positive and false-negative results are also present. In our study, appendix vermiformis was not visualized in $18 \%$, one $(46 / 254)$ of all cases, whether it was 
Table 6. Diagnostic Performance of Alvarado Score Components

\begin{tabular}{|c|c|c|c|c|c|c|}
\hline $\begin{array}{l}\text { Alvarado } \\
\text { Score } \\
\text { Components }\end{array}$ & Specificity (\%95 C.I.) & Sensitivity (\%95 C.I.) & NPV (\%95 C.I.) & PPV (\%95 C.I.) & $\begin{array}{c}\text { Diagnostic } \\
\text { Accuracy }\end{array}$ & AUC (\%95 C.I.) \\
\hline $\begin{array}{l}\text { Migratory } \\
\text { right iliac } \\
\text { fossa pain }\end{array}$ & $90.40 \%(80.6 \%-95.7 \%)$ & $47.50 \%(40.0 \%-55.0 \%)$ & $41.00 \%(33.3 \%-49.0 \%)$ & $92.50 \%(84.5 \%-96.6 \%)$ & $59.8 \%$ & $0.690(0.623-0.756)$ \\
\hline $\begin{array}{l}\text { Nausea/ } \\
\text { vomiting }\end{array}$ & $28.80 \%(19.1 \%-40.7 \%)$ & $62.40 \%(54.9 \%-69.4 \%)$ & $23.60 \%(15.5 \%-34.0 \%)$ & $68.50 \%(60.7 \%-75.4 \%)$ & $52.8 \%$ & $0.456(0.379-0.533)$ \\
\hline Anorexia & $21.90 \%(13.4 \%-33.4 \%)$ & $79.00 \%(72.2 \%-84.5 \%)$ & $29.60 \%(18.3 \%-43.8 \%)$ & $71.50 \%(64.6 \%-77.5 \%)$ & $62.6 \%$ & $0.505(0.426-0.583)$ \\
\hline $\begin{array}{l}\text { Tenderness } \\
\text { inright iliac } \\
\text { fossa }\end{array}$ & $2.70 \%(0.4 \%-10.4 \%)$ & $98.90 \%(95.6 \%-99.8 \%)$ & $50.00 \%(9.2 \%-90.8 \%)$ & $71.60 \%(65.5 \%-77.0 \%)$ & $71.3 \%$ & $0.508(0.429-0.587)$ \\
\hline $\begin{array}{l}\text { Rebound } \\
\text { tenderness } \\
\text { inright iliac } \\
\text { fossa }\end{array}$ & $74.00 \%(62.2 \%-83.2 \%)$ & $52.50 \%(45.0 \%-60.0 \%)$ & $38.60 \%(30.6 \%-47.2 \%)$ & $83.30 \%(75.0 \%-89.4 \%)$ & $58.7 \%$ & $0.632(0.558-0.706)$ \\
\hline $\begin{array}{l}\text { Elevated } \\
\text { temperature }\end{array}$ & $74.00 \%(62.2 \%-83.2 \%)$ & $13.30 \%(8.8 \%-19.3 \%)$ & $25.60 \%(20.0 \%-60.0 \%)$ & $55.80 \%(40.0 \%-70.6 \%)$ & $30.7 \%$ & $0.436(0.356-0.517)$ \\
\hline Leukocytosis & $53.40 \%(41.4 \%-65.0 \%)$ & $83.40 \%(77.0 \%-88.4 \%)$ & $56.50 \%(44.1 \%-68.2 \%)$ & $81.60 \%(75.1 \%-86.8 \%)$ & $74.8 \%$ & $0.684(0.607-0.761)$ \\
\hline $\begin{array}{l}\text { Shift to the } \\
\text { left of } \\
\text { neutrophils }\end{array}$ & $46.60 \%(34.9 \%-58.6 \%)$ & $86.20 \%(80.1 \%-90.7 \%)$ & $57.60 \%(44.1 \%-70.2 \%)$ & $80.00 \%(73.6 \%-85.2 \%)$ & $74.8 \%$ & $0.664(0.585-0.743)$ \\
\hline
\end{tabular}

Abbreviations: AUC, area under curve; NPV, negative predictive value; PPV, positive predictive value; 95\% C.I., 95\% confidence interval.

Table 7. Diagnostic Value of Methods and Their Combinations

\begin{tabular}{|c|c|c|c|c|c|c|}
\hline & Specificity (\%95 C.I.) & Sensitivity (\%95 C.I.) & NPV (\%95 C.I.) & PPV (\%95 C.I.) & $\begin{array}{c}\text { Diagnostic } \\
\text { Accuracy }\end{array}$ & AUC (\%95 C.I.) \\
\hline US & $90.4 \%(80.7 \%-95.7 \%)$ & $73.5 \%(66.3 \%-79.6 \%)$ & $57.9 \%(48.3 \%-67.0 \%)$ & $95.0 \%(89.6 \%-97.8 \%)$ & $78.3 \%$ & $0.819(0.764-0.875)$ \\
\hline $\mathrm{CRP} \geq 0.8$ & $69.9 \%(57.8 \%-79.8 \%)$ & $78.5 \%(71.6 \%-84.1 \%)$ & $56.7 \%(45.8 \%-66.9 \%)$ & $86.6 \%(80.1 \%$ - $91.2 \%)$ & $76.0 \%$ & $0.737(0.658-0.816)$ \\
\hline $\begin{array}{l}\text { Alvarado } \\
\text { Score } \geq 5\end{array}$ & $59.0 \%(46.8 \%-70.1 \%)$ & $86.2 \%(80.0 \%-90.7 \%)$ & $63.1 \%(50.6 \%-74.4 \%)$ & $83.9 \%(77.6 \%-88.9 \%)$ & $78.3 \%$ & $0.776(0.711-0.841)$ \\
\hline $\begin{array}{l}\text { Combinatio } \\
1\end{array}$ & $83.6 \%(72.6 \%-90.8 \%)$ & $69.1 \%(61.7 \%-75.6 \%)$ & $52.1 \%(42.8 \%-61.4 \%)$ & $91.2 \%(84.9 \%-95.2 \%)$ & $73.2 \%$ & $0.763(0.699-0.827)$ \\
\hline Combination & $97.3 \%(89.6 \%-99.5 \%)$ & $51.9 \%(44.4 \%-59.4 \%)$ & $44.9 \%(37.1 \%-53.0 \%)$ & $97.9 \%(91.9 \%-99.6 \%)$ & $65.0 \%$ & $0.746(0.687-0.816)$ \\
\hline
\end{tabular}

2

Abbreviations: AUC, area under curve; CRP, C reactive protein; NPV, negative predictive value; PPV, positive predictive value; US, ultrasound.

normal or inflamed. Twenty six of these 46 patients were found to be acute appendicitis. Similar experiences can be found in the literature $(11,12)$. A reason for false-negative results could be measurement problems specifically in focal appendicitis cases. When the noninflamed part of the appendix is measured, especially the proximal part, appendicitis could be overlooked (13). Visualization of the whole appendix in both longitudinal and transverse planes could be the solution to this problem.

In our study, seven patients had false positive US results. In various diseases, the appendix may have an abnormal appearance, like lymphoid hyperplasia, and cystic fibrosis. Spontaneously resolving acute appendicitis is an- other cause of false positive sonographic results $(14,15)$. Crohn's disease and peritonitis can also mimic acute appendicitis sonographically in case of non-visualization of appendix, by creating secondary signs (16). In the present study, we could not demonstrate other causes of false positive results, but it was seen that five of the seven sonographically false positive patients were lymphoid hyperplasia.

The Alvarado scoring system first described in 1986 provides an early clinical diagnosis of acute appendicitis and lowers the negative appendectomy rates (3). However some prospective studies proposed that Alvarado score on its own was insufficient as a diagnostic tool (17). Consid- 
ering the results of this kind of literature, various studies have been performed to evaluate the diagnostic performance of combinations such as Alvarado score and US or Alvarado score and CRP. Thirumallai's study showed that Alvarado score and CRP taken together improve the predictive value of diagnosing acute appendicitis (18). In our study, results were similar. Combination 1; An Alvarado score of $\geq 5$ and a high CRP level ( $\geq 0.8$ ) had higher PPV than both CRP and Alvarado score.

A metaanalysis about CRP levels in appendicitis reports that CRP serves as a strong predictor for appendiceal perforation, but it is quite limited for appendicitis in general (2). In our study, a high CRP level had neither a sensitivity nor specificity better than other diagnostic parameters. We may conclude that in line with the literature, a high CRP level on its own cannot be used as a diagnostic tool for acute appendicitis, but it can be combined with other methods to increase diagnostic performance.

As expected, when all of our diagnostic parameters were used together, in combination 2, PPV and specificity increased. Unfortunately, we cannot detect all acute appendicitis cases by using combination 2. When Alvarado score is higher than 6, CRP levels are higher than $4 \mathrm{mg} / \mathrm{L}$, and there is a US report indicating inflamed or perforated appendix, then the specificity and PPV increases to $100 \%$. In equivocal cases, combinations of mentioned methods can solve the problem.

However, in cases without positive sonographic findings of an inflamed or perforated appendix, even if both Alvarado score and CRP levels are high, we might have a "not acute appendicitis" pathology result. In these cases, CT is still the method of choice, in spite of ionizing radiation.

If Alvarado score is below 5 and CRP levels are in the normal range, we still need an US report indicating normal appendix to exclude acute appendicitis safely.

Most patients presenting with symptoms of acute appendicitis are younger, and when they are exposed to radiation by CT scan, the lifetime risk of developing cancer is believed to increase (19). Therefore, CT scanning should be employed more judiciously. Use of the Alvarado score, US, and CRP in combination will enable us to use CT when it is really needed.

The main limitation of the present study was that we excluded the patients whose medical reports were not sufficient for Alvarado scoring, and did not have a CRP value. US examinations were performed by different radiologists who have 1 - 3 years of experience. Hence, our study findings may not be applicable to physicians who perform US examinations or radiologists to have more/less experience. Another limitation is that we cannot present separate results for pediatric and adult population because of insufficient pediatric patient numbers. In addition, we cannot evaluate inter-intra observer reliability because each radiologist's data were not collected separately. Further studies examining these reliability ratios might be able to add much to the literature.

To conclude, combination of Alvarado score, US, and CRP levels enables us to safely confirm or rule out acute appendicitis diagnosis. Therefore, unnecessary CT scans and negative appendectomy rates may decrease. Moreover, CT might still be needed in some equivocal cases.

\section{Footnotes}

Authors' Contribution: None declared.

Financial Disclosure: None declared.

Funding/Support: None declared.

\section{References}

1. Gwynn LK. The diagnosis of acute appendicitis: clinical assessment versus computed tomography evaluation.JEmerg Med. 2001;21(2):11923. [PubMed: 11489398].

2. Shogilev DJ, Duus N, Odom SR, Shapiro NI. Diagnosing appendicitis: evidence-based review of the diagnostic approach in 2014. West J Emerg Med. 2014;15(7):859-71. doi: 10.5811/westjem.2014.9.21568. [PubMed: 25493136].

3. Apisarnthanarak P, Suvannarerg V, Pattaranutaporn P, Charoensak A, Raman SS, Apisarnthanarak A. Alvarado score: can it reduce unnecessary CT scans for evaluation of acute appendicitis?. Am J Emerg Med. 2015;33(2):266-70. doi: 10.1016/j.ajem.2014.11.056. [PubMed: 25542452].

4. Toprak H, Kilincaslan H, Ahmad IC, Yildiz S, Bilgin M, Sharifov R, et al. Integration of ultrasound findings with Alvarado score in children with suspected appendicitis. Pediatr Int. 2014;56(1):95-9. doi: 10.1111/ped.12197. [PubMed: 23937630].

5. Andersson RE. Meta-analysis of the clinical and laboratory diagnosis of appendicitis. Br J Surg. 2004;91(1):28-37. doi: 10.1002/bjs.4464. [PubMed: 14716790].

6. Puylaert JB. Acute appendicitis: US evaluation using graded compression. Radiology. 1986;158(2):355-60. doi: 10.1148/radiology.158.2.2934762. [PubMed: 2934762].

7. Al-Abed YA, Alobaid N, Myint F. Diagnostic markers in acute appendicitis. Am J Surg. 2015;209(6):1043-7. doi: 10.1016/j.amjsurg.2014.05.024. [PubMed: 25172166].

8. Al-Khayal KA, Al-Omran MA. Computed tomography and ultrasonography in the diagnosis of equivocal acute appendicitis. A metaanalysis. Saudi Med J. 2007;28(2):173-80. [PubMed: 17268692].

9. Doria AS, Moineddin R, Kellenberger CJ, Epelman M, Beyene J, Schuh S, et al. US or CT for Diagnosis of Appendicitis in Children and Adults? A Meta-Analysis. Radiology. 2006;241(1):83-94. doi: 10.1148/radiol.2411050913. [PubMed: 16928974].

10. Carroll PJ, Gibson D, El-Faedy O, Dunne C, Coffey C, Hannigan A, et al. Surgeon-performed ultrasound at the bedside for the detection of appendicitis and gallstones: systematic review and meta-analysis. Am J Surg. 2013;205(1):102-8. doi: 10.1016/j.amjsurg.2012.02.017. [PubMed: 22748292].

11. Kurane SB, Sangolli MS, Gogate AS. A one year prospective study to compare and evaluate diagnostic accuracy of modified Alvarado score and ultrasonography in acute appendicitis, in adults. Indian J Surg. 2008;70(3):125-9. doi: 10.1007/s12262-008-0035-7. [PubMed: 23133039]. 
12. Nasiri S, Mohebbi F, Sodagari N, Hedayat A. Diagnostic values of ultrasound and the Modified Alvarado Scoring System in acute appendicitis. Int J Emerg Med. 2012;5(1):26. doi: 10.1186/1865-1380-5-26. [PubMed: 22673121].

13. Lim HK, Lee WJ, Lee SJ, Namgung S, Lim JH. Focal appendicitis confined to the tip: diagnosis at US. Radiology. 1996;200(3):799-801. doi: 10.1148/radiology.200.3.8756934. [PubMed: 8756934].

14. Puylaert JB. Ultrasonography of the acute abdomen: gastrointestinal conditions. Radiol Clin North Am. 2003;41(6):1227-42. [PubMed: 14661668] vii.

15. Migraine S, Atri M, Bret PM, Lough JO, Hinchey JE. Spontaneously resolving acute appendicitis: clinical and sonographic documentation. Radiology. 1997;205(1):55-8. doi: 10.1148/radiology.205.1.9314962. [PubMed: 9314962].
16. Wiersma F, Toorenvliet BR, Bloem JL, Allema JH, Holscher HC. US examination of the appendix in children with suspected appendicitis: the additional value of secondary signs. Eur Radiol. 2009;19(2):455-61. doi: 10.1007/s00330-008-1176-6. [PubMed: 18815791].

17. Macklin CP, Radcliffe GS, Merei JM, Stringer MD. A prospective evaluation of the modified Alvarado score for acute appendicitis in children. Ann R Coll Surg Engl. 1997;79(3):203-5. [PubMed: 9196342].

18. Thirumallai S, Wijesuriya SR, Mitchell A, Delriviere L. Predictive value of C-reactive protein with Alvarado score in acute appendicitis. ANZJ Surg. 2014;84(5):335-6. doi: 10.1111/ans.12408. [PubMed: 24119072].

19. Brenner DJ, Hall EJ. Computed tomography-an increasing source of radiation exposure. $N$ Engl J Med. 2007;357(22):2277-84. doi: 10.1056/NEJMra072149. [PubMed: 18046031]. 